\title{
INFLUENCE OF TRANSITION LOCATION ON AIRFOIL DRAG
}

\author{
E. Lasauskas
}

VGTU Antanas Gustaitis Aviation Institute, Rodūnès kelias 30,LT-02187Vilnius, Lithuania.E-mail: Edulas@ai.vtu.lt Received 2306 2005, accepted 29082005

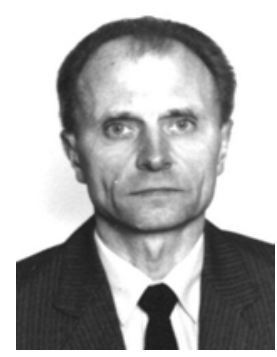

Eduardas LASAUSKAS, Assoc. Prof.

Date of birth: 1952

Education: 1976 - Diploma degree in aircraft mechanical engineering, Kazan Aircraft Institute, 2000 - Doctoral degree in mechanical engineering, Vilnius Gediminas Technical University.

Professional experience: March 1976 - Jule 1998 Aerodynamics engineer at Joint Stock Company "Sportine aviacija".

Research interest: Low speed wing aerodynamics.

Professional membership: Member of Organisation Scientifique et Technique du Vol à Voile (OSTIV)

Teaching: Aerodynamics, Flight dynamics.

Present position: Head of department of aviation mechanics of Antanas Gustaitis Aviation Institute of Vilnius Gediminas Technical University.

\begin{abstract}
A comparison of predicted and measured laminar-turbulent transition on the airfoil is presented. The MSES code is used for a prediction. The experimental data are taken from an experiment of W. Würz. Comparison of calculated results with measured data shows that the envelope of calculated individual frequencies coincides well with measured data in the transitional region for the attached boundary layer and for the separated laminar shear layer. For minimum drag, the laminar flow should be as long as possible and the shape parameter of the boundary layer at the transition should not exceed the value of 3.8. The optimum value of the shape parameter is 3.65 at Reynolds numbers from 1 to 2 million.
\end{abstract}

Keywords: laminar - turbulent transition, linear stability theory, $e^{n}$ method, laminar separation bubble, drag.

\section{Introduction}

At Reynolds numbers below 5 million, airfoils are affected by laminar separation bubbles, which in many cases considerably increase the drag [6]. One way to decrease overall drag rise over the bubble is to shorten it by forcing transition farther upstream. Clearly, an optimum transition location exists, usually close to the laminar separation point [1]. Exact prediction of transition is therefore important for design optimisation of airfoils.

The process of transition from laminar to turbulent flow remains one of the most important unsolved problems in fluid mechanics. Transitional flows are characterised by increased skin friction, and the accurate determination of drag depends on the ability to predict the transition. However, no mathematical model exists that can accurately predict the location of transition under a wide range of conditions. Design engineers resort to methods that are based on either empirical correlations or linear stability theory, for example the $e^{n}$ method [1].

For the purpose of computing aerodynamic flows, the $\mathrm{e}^{\mathrm{n}}$ method is in principle applicable to any type of viscous flow calculation method that can provide a mean flow profile $u(y)$ in the boundary layer. The source of difficulty is the considerable cost of solving the OrrSommerfeld equation at each control point. The solution must be generated at every iteration, at every stream wise location, and for a range of frequencies, which altogether can easily exceed the cost of solving the flow equations. A major simplification is to attempt to track only the maximum envelope of all the frequencies, as in the modified envelope method of Drela and Giles [3]. This envelope method is implemented into the MSES viscous/in viscid solver and in the XFOIL code [4, 9]. To permit the validity of the results of the envelope method to be checked, the MSES displays both the envelope and the individual frequencies that would have been predicted by the $e^{n}$ method.

One purpose of this article is to compare the predicted growth of Tolmien-Schlichting waves in the attached and separated laminar boundary layer using the envelope method and individual frequencies with the precise measured results of W. Würz [9]. Another purpose of this article is to analyse the influence of laminar-turbulent transition location on the drag.

\section{Comparison of calculated and measured transition location}

The calculated growth of Tolmien-Schlichting waves on an XIS40MOD airfoil is compared with the measured results of W. Würz [9]. The XIS40MOD airfoil, depending on the angle of attack, allows the development of the boundary layer in the attached boundary layer and laminar separation bubble to be analysed.

Fig 1 shows the comparison of calculated growth of Tolmien-Schlichting waves using MSES code with the measured data of $\mathrm{W}$. Würz in the laminar separation bubble. The parameter $n$ is the logarithm of the amplification factor of the Tolmien-Schlichting wave amplitude. A suitable value for this parameter depends on the ambient disturbance level. The thin lines correspond to Tolmien-Schlichting wave amplitude growth of individual frequencies. The thick line is the result of the simplified envelope method. Stars show the true envelope 
from measurement. The slow amplitude growth is in the attached laminar boundary layer until separation at approximately $70 \%$ of chord. The calculated values are lower than the measured values in this region. After separation, the growth of amplitude is much quicker.

The envelope of calculated individual frequencies coincides very well with measured data in this region. The transition occurs at the $n=12$. The envelope of calculated individual frequencies predicts the transition location in this case very well. The $n$ value from simplified envelope at the transition is 9.4 .

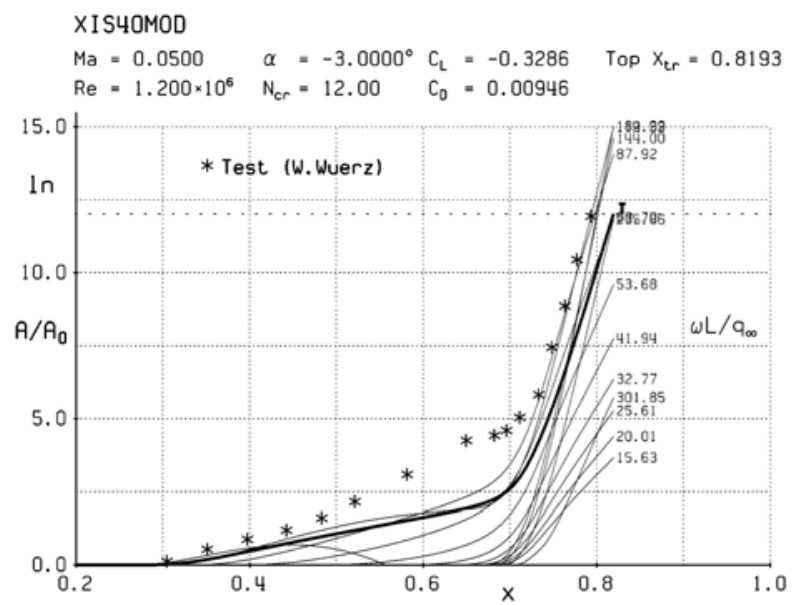

Fig 1. Comparison of calculated (MSES) growth of TolmienSchlichting waves with the measured data of W. Würz [9] in the laminar separation bubble. The thick line corresponds to the simplified envelope method

Fig 2 shows the comparison of calculated growth of Tolmien-Schlichting waves using MSES code with the measured data of $\mathrm{W}$. Würz in the attached laminar boundary layer. The calculated values are higher than the measured values in this case.

The transition occurs at the $n=12$. The $n$ value from the envelope of calculated individual frequencies is equal to 12.8 at this position. The difference of the measured and predicted transition location is 0.02 of wing section chord. The $n$ value from the simplified envelope at the transition is 8.7 .

The standard value of $n$ in the simplified envelope method of XFOIL code is 9 . This value approximately models the transition location in the attached and separated boundary layer if the true $n$ value at the transition is 12 .

In general, the true $n$ value at the transition depends on the turbulence level in the free stream. The highest true $n$ value, 15 , is reached in free flight.

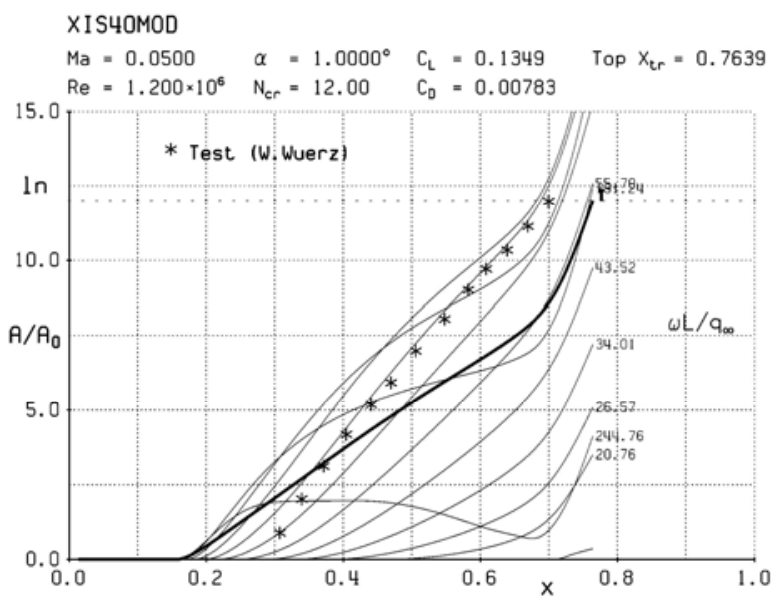

Fig 2. Comparison of calculated (MSES) growth of Tolmien-Schlichting waves with the measured data of W. Würz [9] in the attached boundary layer

\section{Influence of transition location on drag of wing section}

The low drag of a wing section can be achieved by the design of long laminar flow regions on the upper and lower surface. At Reynolds numbers below 5 million, airfoils are affected by laminar separation bubbles, which in many cases considerably increase the drag. The longer laminar flow region is, the more is the tendency to laminar separation bubble. An optimum transition location exists for minimum drag.

Fig 3 shows a typical section of a high performance sailplane wing and pressure distribution at $C_{L}=0.44$. The laminar flow on the lower side goes up to $78 \%$ of chord, and transition is fixed at this position. The laminar flow on the upper side goes up to $72 \%$ of chord. The transition is free on the upper side. It is predicted at $n=12$ using the envelope of individual frequencies.

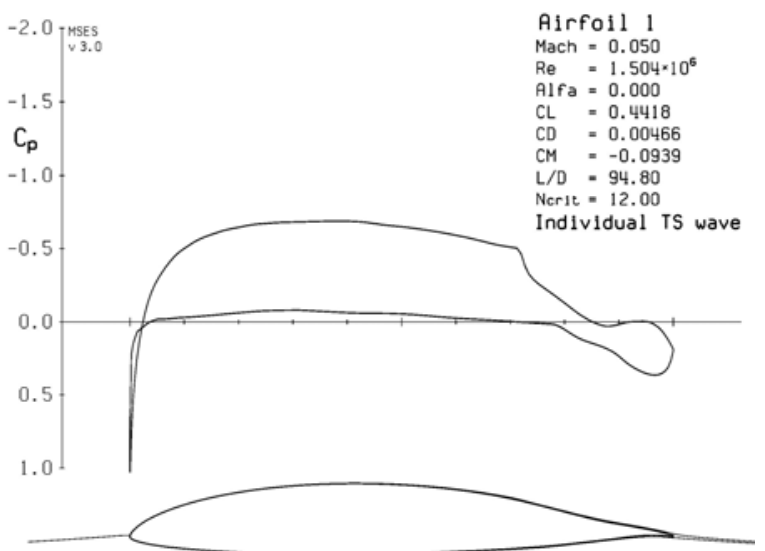

Fig 3. Pressure distribution on a typical section of sailplane wing

If we set a higher value, for example, $n=16$, and fix the transition before natural transition at different stations, we can find the optimum position of transition for minimum drag.

Fig 4 shows the drag coefficient of this wing section versus transition location on the upper side at $\alpha=0$. The minimum drag of the wing section is achieved if the 
transition is at $70 \%$ of chord. The shape of the curve at this optimal region is flat. This means that a small deviation from the optimal transition location does not affect the wing section drag.

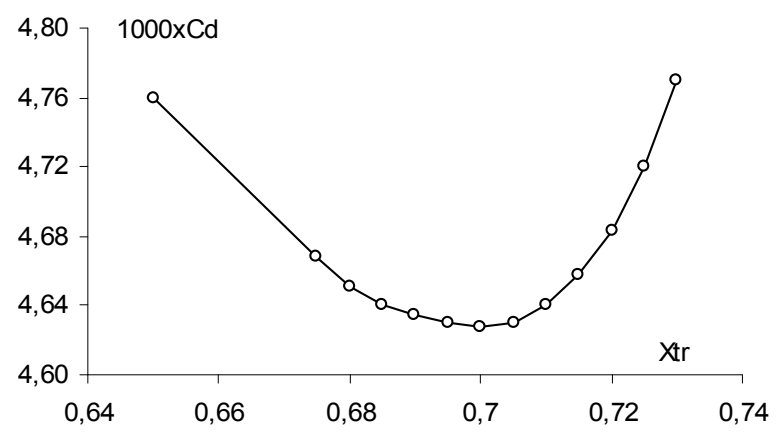

Fig 4. Calculated (MSES) drag coefficient of airfoil 1 versus transition location at $\alpha=0$

It would be useful to relate the minimum drag with the boundary layer parameters at the transition. Fig 5 shows the length of laminar separation bubble $S s$ on the upper side of airfoil 1 versus transition location at $\alpha=0$. If the transition is below $70.5 \%$ of chord, it occurs in the attached boundary layer. Farther downstream, transition occurs in the separated shear layer. Drag is minimal if the transition is at $70 \%$ of chord, just before separation.

Another parameter of boundary layer that can be related to the minimum drag is the shape parameter $H_{K}$. Shape parameter $H_{K}$ is the ratio of displacement to the momentum thickness of the boundary layer. Fig 6 shows the shape parameter $H_{K}$ on the upper side versus chord if the transition is forced at 0.70 of chord. The maximum value is at the transition. If we force the transition at different location of chord, we can get the shape parameter $H_{K}$ of boundary layer at the transition on the upper side versus transition location. This is shown in Fig 7. The shape parameter continually grows with transition location. So it is possible to analyse drag coefficient versus shape parameter.

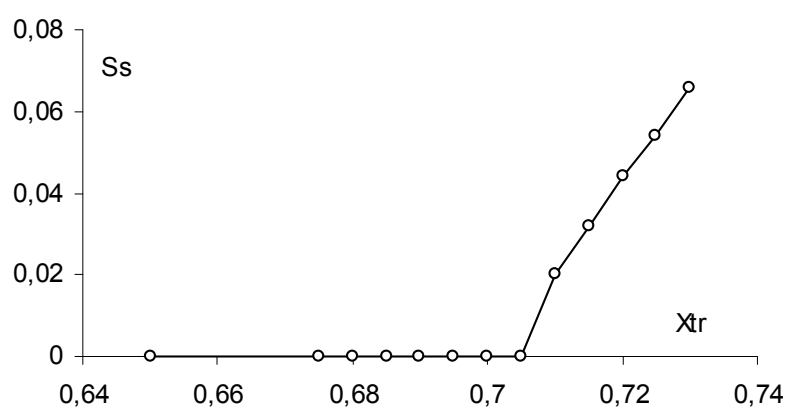

Fig 5. Calculated (MSES) length of laminar separation bubble on the upper side of airfoil 1 versus forced transition location at $\alpha=0$

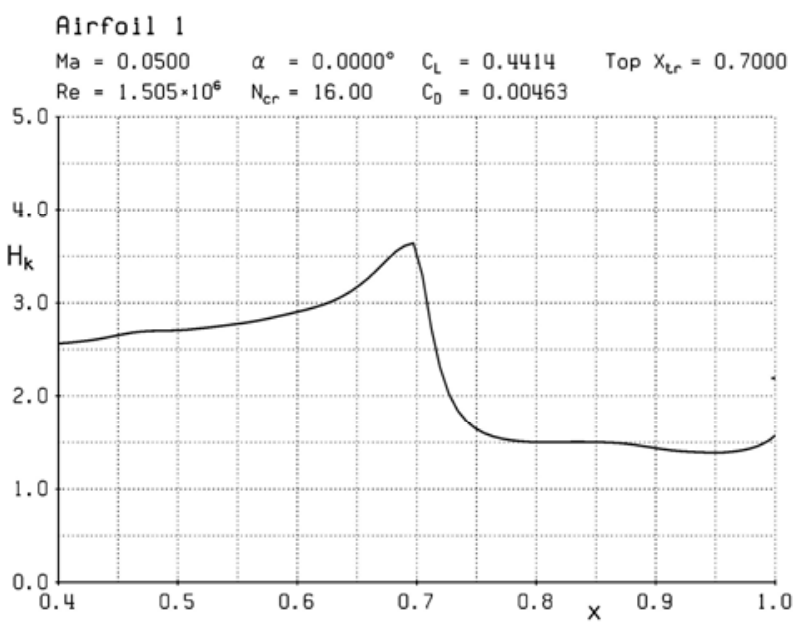

Fig 6. Calculated (MSES) shape parameter $H_{K}$ on the upper side of airfoil 1 versus chord position at $\alpha=0$

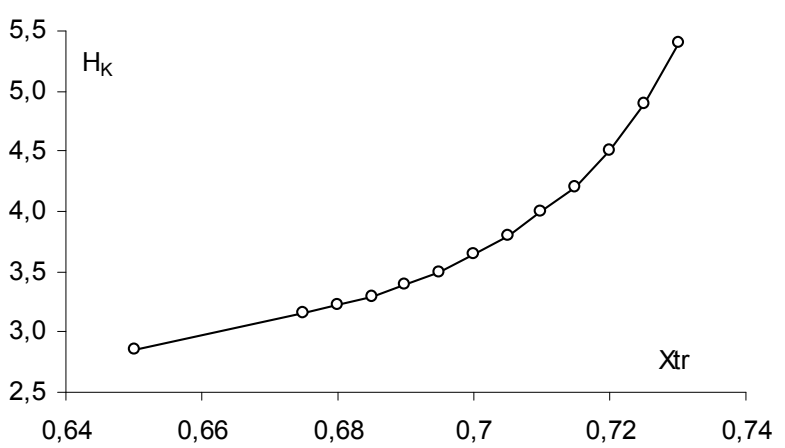

Fig 7. Calculated (MSES) shape parameter $H_{K}$ at the transition versus forced transition location on the upper side of airfoil 1 at $\alpha=0$

Fig 8 shows the drag coefficient versus shape parameter $H_{K}$ of the boundary layer at the transition on the upper side of airfoil 1 versus transition location at $\alpha=0$. Drag coefficient is minimal when the shape parameter is $H_{K}=3.65$. Fig 9 and 10 shows the same function for $-1.5^{\circ}$ and $2^{\circ}$ angles of attack. The minimum drag is also approximately at $H_{K}=3.65$. The curves in the minimum region are flat. If the shape parameter does not exceed the value $H_{K}=3.8$, the drag is near the minimum.

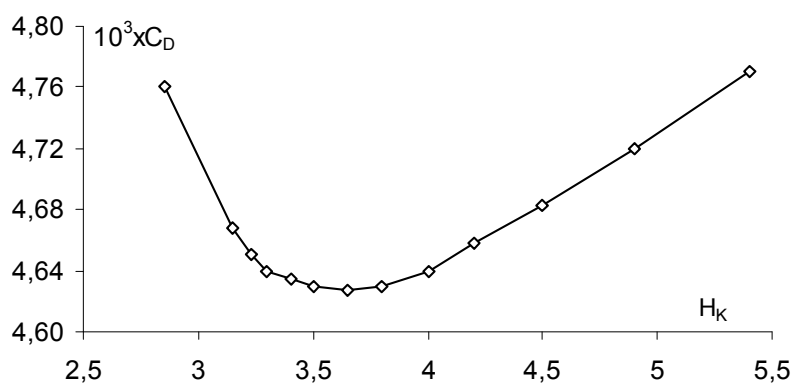

Fig 8. Calculated (MSES) drag coefficient of airfoil 1 versus shape parameter $H_{K}$ at the transition on the upper side at $\alpha=0$ 
Table. Flow conditions at different angles of attack

\begin{tabular}{|c|c|c|}
\hline$\alpha$ & $C_{L}$ & $R e$ \\
\hline$-1.5^{\circ}$ & 0.266 & $1.93 \cdot 10^{6}$ \\
\hline $0^{\circ}$ & 0.442 & $1.50 \cdot 10^{6}$ \\
\hline $2^{\circ}$ & 0.672 & $1.22 \cdot 10^{6}$ \\
\hline
\end{tabular}

Flow conditions at different angles of attack are presented in table. The Reynolds number is related to the constant lift conditions. It corresponds to level flight conditions of an aircraft.

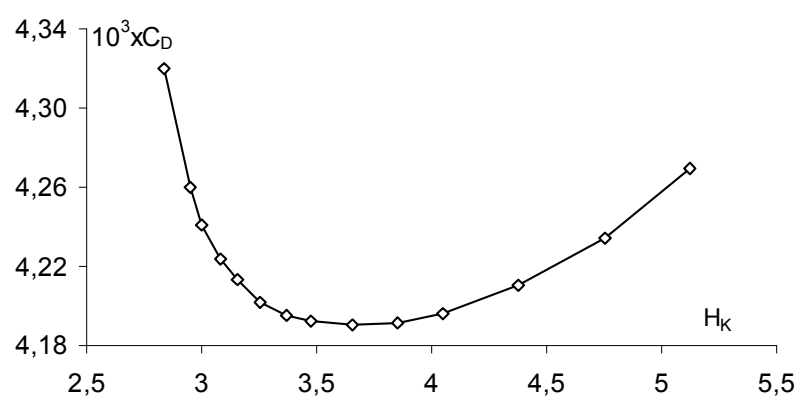

Fig 9. Calculated (MSES) drag coefficient of airfoil 1 versus shape parameter $H_{K}$ at the transition on the up-per side versus forced transition location at $\alpha=-1.5^{\circ}$

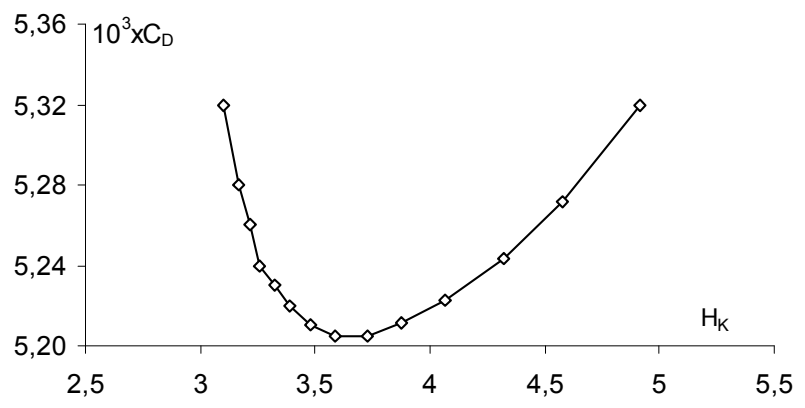

Fig 10. Calculated (MSES) drag coefficient of airfoil 1 versus shape parameter $H_{K}$ at the transition on the upper side versus forced transition location at $\alpha=2^{\circ}$

So, for minimum drag, the laminar flow on the airfoil should be as long as possible, and the shape parameter at the free transition should not exceed the value of 3.8. This is not difficult using modern methods of airfoil design [5]. Predicted airfoil characteristics can be used later for calculation of finite span wings [Error! Reference source not found.].

\section{Conclusions}

Comparison of the calculated results with measured data shows that the envelope of calculated individual frequencies coincides well with measured data in the transitional region for the attached boundary layer and for the separated laminar shear layer.

For minimum drag, the laminar flow should be as long as possible and the shape parameter at the transition should not exceed the value of 3.8. The optimum value of the shape parameter is 3.65 at Reynolds numbers from 1 to 2 million.

\section{References}

1. Drela M. Implicit Implementation of the Full $\mathrm{e}^{\mathrm{n}}$ Transition Criterion // AIAA Paper 40662003. - 2003.

2. Drela M. Low-Reynolds Number Airfoil Design for the MIT Daedalus Prototype: A Case Study // Journal of Aircraft. - 1988. - Vol 25. - P. 724-732.

3. Drela M. XFOIL: An Analysis and Design System for Low Reynolds Number Airfoils // Proceedings of the Conference Notre Dame, Indiana, June 5-7, 1989. - New York: Springer-Verlag, 1989. - P.1-12.

4. Drela, M., Giles M. Viscous-inviscid Analysis of Transonic and Low Reynolds Number Airfoils // AIAA Journal. - 1987. -Vol 25. - P. 1347-1355.

5. Eppler R. Airfoil design and data. - Berlin: Springer-Verlag, 1992. - $562 \mathrm{p}$.

6. Horstmann K. -H., Quast A., Boermans L.M.M. Pneumatic Turbulators - A Device for Drag Reduction // AGARD CP 365. - 1984. Paper 20.

7. Horstmann K. -H., Quast A., Redeker G. Flight and Wind-Tunnel Investigations on Boundary-Layer Transition. // Journal of Aircraft. - 1992. - Vol 27. - P. 146-150.

8. Lasauskas E., Pakalnis E., Stankūnas J. A System of Nonlinear Equations for Wing Lift Calculation. //Aviation. - Vilnius: Technika, 2002. Vol 6. - p. 50-54.

9. Würz W. Hitzdrahtmessungen zum laminarturbulen-ten Strömungsumschlag in anliegenden Grenzschichten und Ablöseblasen sowie Vergleich mit der linearen Stabilitätstheorie und empirischen Umschlagskriterien: Dissertation. - Universität Stuttgart, 1995. - 147 s. 